\title{
Metode Weighted Product Pada Sistem Pendukung Keputusan Pemberian Bonus Pegawai Pada CV Bejo Perkasa
}

\author{
Agung Sugiarto ${ }^{1}$, Robby Rizky $^{2}$, Susilawati ${ }^{3}$, Ayu Mira Yunita ${ }^{4}$, Zaenal Hakim ${ }^{5}$ \\ Universitas Mathla'ul Anwar ${ }^{1,2,3,4}$ \\ agung860@gmail.com ${ }^{1}$,robbybae87@yahoo.com ${ }^{2}$, susilawatititki122@gmail.com ${ }^{3}$, \\ ayumirayunita@gmail.com ${ }^{4}$, baduykidul@gmail.com $^{5}$
}

\begin{abstract}
Abstrak - Penelitian ini membahas tentang permasalahan yang ada di lingkungan perusahaan cv bejo perkasa dimana permasalahanya yaitu memberikan bonus pegawai yang berada di lingkungan cv bejo perkasa.pemberianya sangat tidak merata dan tidak sesuai dengan kinerja pegawainya.tujuan dari penelitian ini adalah bagaimana agar bonus karyawan dapat diberikan secara adil sesuai kinerja pegawai itu sendiri karyawan yang akan mendapatkan bonus tersebut harus memenuhi kriteria diantaranya yaitu kreatifitas, absensi, profesionalitas, kebersihan, kerjasama, tanggung jawab, tatakrama dan penampilan yang sudah ditentukan oleh perusahaan agar perhitungan pemberian bonus lebih tepat sasaran maka akan diolah oleh metode Wighted Product. Metode WP merupakan metode pengambilan keputusan dengan cara perkalian untuk menghubungkan rating atribut, rating setiap atribut harus di pangkatkan dulu dengan bobot atribut yang bersangkutan.data yang digunakan dalam penelitian ini yaitu data dari hasil wawancara berupa kuesioner yang nanti diolah oleh metode WP tersebut. Hasil dari penelitian ini yaitu pemberian bonus terhadap karyawan akan merata dan adil sesuai kinerja pegawai tersebut dan berdampak pada kinerja pegawai yang rajin jika mendapatkan bonus akan semakin semangat dalam melakukan pekerjaan kedepanya jika pegawai yang sudah rajin semakin rajin akan berdampak pada perusahaan. Kesimpulan pada penelitian ini metode WP sangat cocok untuk penelitian ini.
\end{abstract}

Kata Kunci : sistem pendukung keputusan,metode, Weighted Product, pemberian bonus, karyawan

\begin{abstract}
This study discusses about the problems in Bejo Perkasa CV., that is related to the distribution of employee bonuses that are unfair. It's not accordance with the employee performance. The purpose of this study is how to give a fair bonus according to employee performance. Employees who will get the bonus must have the criteria including creativity, absenteeism, professionalism, cleanliness, cooperation, responsibility, manners and appearance as determined by the company. For good calculating on target, the data is processed using the Wighted Product method. It's a method of decision making by multiplying to link attribute ratings, where the rating of each attribute must be raised first with the weighted of it. The data used in this study is data from the results of interviews in the form of a questionnaire that was processed by the WP method. The results of this is giving bonuses to employees will be even and fair and have an impact on employee performance diligently. If they get a bonus, they will be more enthusiastic in doing the work. Furthermore, the presence of qualified employees will contribute more to the company. In conclusion, the WP method is very suitable for this research.

Keywords: decision support system,method, Weighted Product, bonus giving, the employee
\end{abstract}

\section{PENDAHULUAN}

Disetiap perusahaan, instansi, organisasi atau badan usaha akan meberikan gaji sebagai konpensasi dari kerja seorang karyawan pemberian bonus tersebut adalah sebagai penyemangat karyawan tersebut dalam bekerja maka dari pemberian bonus terhadap karyawan sangat diperlukan(Ainun et al., 2017).perbedaan dengan penelitian sebelumnya yaitu kebanyakan tidak menggunakan metodologi jadi ketika akan memberikan bonus terhadap karyawan tidak menggunakan perhitungan yang sangat matang, menjadikan pemberian bonus terhadap pegawai menjadi tidak merata,pemberian bonus bida di karnakan kedekatan emosional atau kedekatan dengan pemilik perusahaan atau sanak sodara yang mendapatkan bonus lebih besar dengan di adanyaknya motode WP ini mengurangi kecurangan tersebut. Pada saat ini beberapa sistem perusahaan yang berjalan untuk menentukan bonus masih di lakukan secara manual kepada setiap karyawan yang ada. Dalam upaya untuk mendapatkan data yang akurat dengan keadaan karyawan di perusahaan,maka penyusunan melakukan penelitian dan wawancara beberapa karyawan yang ada yang dilakukan oleh penyusun, dapat disimpulkan bahwa karyawan sering merasakan tidak 
meratanya pembagian bonus pada setiap karyawan(Marbun et al., 2018). Karyawan merupakan bagian terpenting dalam perusahaan sukses tidak suatu perusahaan tergantung pada kinerja setiap karyawanya untuk menjaga kesetabilan kinerja karyawan agar selalu semangat dan menjaga kesetabilan kinerja karyawan agar selalu semangat dan termotifasi(Putra et al., 2016). Sistem pendukung keputusan merupakan sistem informasi interaktif yang menyediakan informasi,pemodelan dan pemanipulasian data(Sambani et al., 2016).

Beberapa penelitian yang dijadikan referensi untuk penelitian ini yaitu membahasa penetilitian yang menggunakan metoda Weighted product antara lain keputusan pemberian kredit pensiun menggunakan metode Weighted Product(Naramessakh \& Prianto, 2019), serta penelitian yang berjudul implementasi aplikasi sistem pendukung keputusan kenaikan jabatan pegawai negeri sipil (PNS) menggunakan metode Weighted Product pada bagian protocol dan dokumentasi setda depok(Irsan, 2018), serta penelitian penetuan bonus karyawan menggunakan Weighted Product pada perusahaan agro bisnis palu(Syafitri \& Dewi, 2016), serta penelitian pemilihan siswa berprestasi menggunakan metode Weighted product (WP) studi kasus smp - Al fitroh tanggerang(T. Hidayat \& Komariah, 2020), serta penelitian sistem pendukung keputusan pemilihan dosen terbaik dengan metode Weighted Product (WP) pada STMIK ROYAL(Marpaung et al., 2018),serta penelitian penentuan pemenang lomba Cosplay berbasis Weighted Product(M. A. Hidayat et al., 2015). Serta penelitian perancangan sistem pendukung keputusan penetuan prioritas produk unggulan daerah menggunakan metode Weighted Product WP(Syafitri \& Dewi, 2016). Serta penelitian penerapan metode weighted aggregated sum product assessment menentukan tepung terbaik untuk memproduksi bihun (Marbun et al., 2018). Serta penelitian penerapan metode Weighted Product model untuk seleksi calon karyawan (Lestari, 2013). Serta penelitian pemilihan rumah tinggal menggunakan metode Weighted Product (Supriyono, 2015). Serta penelitian sistem pendukung keputusan untuk menentukan pelanggan terbaik pada TB bangun jaya menggunakan metode Weighted product (WP)
(Oktaviana \& Himawan, 2015). Penentuan sekolah dasar negeri terbaik kota Palembang dengan metode Weighted sum model (WSM)dan Weighted product model (WPM) menggunakan visual basic.net 2015 (Putra et al., 2016). serta penelitian sistem pendukung keputusan penentuan bonus sales di PT master dumai dengan metode SAW(simple additive Weighting)(Lestari, 2013).

\section{METODOLOGI PENELITIAN}

A. Metode Pengumpulan Data

Pada penelitian ini,dalam pengumpulan data menerapkan 3 metode, yang pertaman metode wawancara, peneliti mengumpulkan data dengan cata bertanya kepada para pakar di bidangnya secara langsung. Metode kedua yang peneliti lakukan adalah melakukan pengamatan secara langsung terhadap objek penelitian, dengan cara melakukan pencatatan secara langsung terhadap kejadian kejadian yang sedang di teliti. Dan metode terakhir adalah studi pustaka pengumpulan data yang di lakukan dengan membaca buku-buku literature,jurnal,internet,majalah,dan penelitian terdahulu yang berkaitan dengan penelitian yang sedang di lakukan.

\section{B. Metode Analisis Data}

Metode Analisis data yang peneliti lakukan adalah menganalisaperhitungan dengan menggunakan metode Weighted Product agar kedepanya data tersebut dapat di aplikasikan ke dalam sebuah perusahaan.

C. Tahapan Penelitian

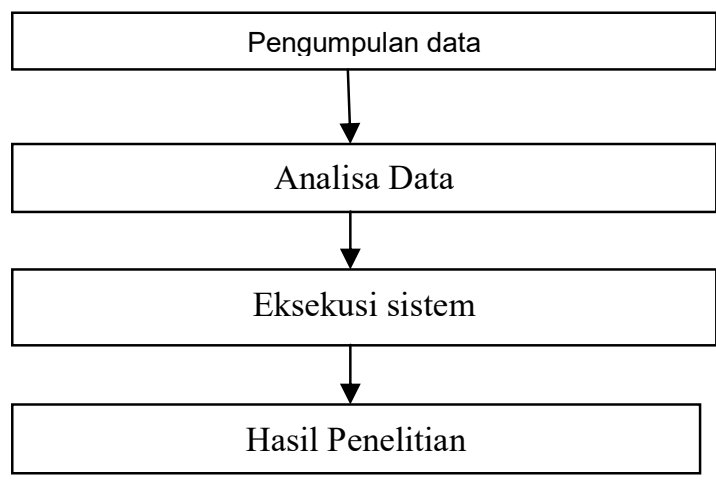

Gambar 1 Tahapan Penelitian Sumber :(Supriyono, 2015)

Keterangan :

1. Pengumpulan data :

istilah asing teknik pengumpulan data adalah proses formal menggunakan teknik seperti wawancara dan daftar pertanyaan kuesioner untuk mengumpulkan fakta tentang sistem,kebutuhan dan pilihan. 
2. Analisa data

Analisa data dalam penelitian ini yaitu suatu kegiatan yang di lakukan untuk mengubah data hasil dari penelitian menjadi sebuah informasi baru yang dapat di gunakan dalam sebuah kesimpulan data yang sudah di dapat nanti akan di hitung menggunakan algoritma Weighted Produck alas an menggunakan algoritma Weighted Produck agar akurat perhitungan nya.

3. Eksekusi sistem :

Tahapan ini adalah tahapan memasukan hasil dari pengolahan data tersebut yang nanti akan di tuangkan ke dalam sistem aplikasi

Data yang di gunakan pada penelitian ini adalah hasil dari wawancara sehingga mendapatkan data yang memadai untuk di teliti.

Tabel 1 Kriteria Penialian

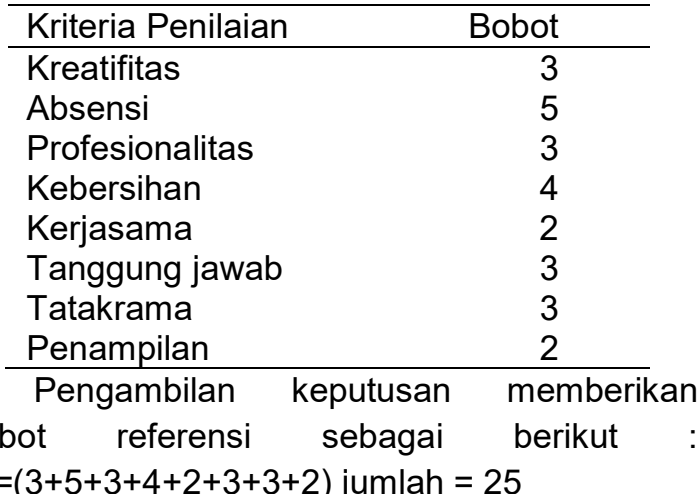

Selanjutya yaitu langkah langkah pembahasan tahap tahapanya yaitu membagi masing masing nilai, menetukan nilai kriteria, pemberian bobot alternative ,menghitung nilai vector SI,langkah terakhir yaitu menghitung nilai vector $\mathrm{Vi}$.

\section{HASIL DAN PEMBAHASAN}

Langkah yang di lakukan dalam penelitian ini menggunakan metode Weighted product adalah dilakukan perbaikan bobot terlebih dahulu maka pangkat di peroleh dari jumlah $\mathrm{W}$ di bagi masing masing nilai dari kriteria yang sudah ditentukan, dan hasilnya adalah :

$$
\begin{aligned}
& W_{1}=\frac{3}{3+5+3+4+2+3+3+2}=0.12 \\
& W_{2}=\frac{3}{3+5+3+4+2+3+3+2}=0,12 \\
& W_{3}=\frac{5}{3+5+3+4+2+3+3+2}=0,20 \\
& W_{4}=\frac{4}{3+5+3+4+2+3+3+2}=0,16
\end{aligned}
$$

$$
W_{5}=\frac{2}{3+5+3+4+2+3+3+2}=0,08
$$$$
W_{7}=\frac{3}{3+5+3+4+2+3+3+2}=0,12
$$

$$
W_{6}=\frac{3}{3+5+3+4+2+3+3+2}=0,12
$$

$$
W_{8}=\frac{2}{3+5+3+4+2+3+3+2}=0,08
$$

$\sum w=0,12+0,20+0,12+0,16+0,08+0,12+$ $0,12+0,08=1$

Tabel 2 Nilai Kriteria perbaikan bobot

\begin{tabular}{lcc}
\hline Nama_kriteria & Bobot & $\begin{array}{c}\text { Perbaikan } \\
\text { Bobot }\end{array}$ \\
\hline Kreatifitas & 3 & 0.12 \\
Absensi & 5 & 0.20 \\
Profesionalitas & 3 & 0.12 \\
Kebersihan & 4 & 0.16 \\
Kerjasama & 2 & 0.08 \\
Tanggung jawab & 3 & 0.12 \\
Tata karma & 3 & 0.12 \\
Penampilan & 2 & 0.08 \\
\hline
\end{tabular}

Pemberian bobot Alternatif

Di bawah ini penulis paparkan pemberian bobot kepada setiap karyawan untuk masing masing kriteria :

Tabel 3 pemberian bobot Alternatif

\begin{tabular}{lllllllll}
\hline \multicolumn{1}{c}{$\begin{array}{c}\text { Nama } \\
\text { Karyawan }\end{array}$} & KF & AB & PR & KB & KR & TJ & TK & PN \\
\hline Wawan & 80 & 85 & 75 & 80 & 50 & 60 & 70 & 70 \\
Andi & 70 & 80 & 70 & 85 & 65 & 80 & 75 & 75 \\
Pitri & 70 & 70 & 75 & 80 & 75 & 85 & 75 & 80 \\
Suryana & 85 & 70 & 65 & 60 & 80 & 55 & 65 & 75 \\
Agus & 65 & 80 & 65 & 75 & 70 & 65 & 80 & 65 \\
Dudi & 70 & 75 & 65 & 50 & 55 & 65 & 60 & 70 \\
Asep & 75 & 80 & 80 & 85 & 70 & 65 & 60 & 70 \\
Topik & 80 & 90 & 85 & 70 & 50 & 60 & 75 & 85 \\
Sukisno & 55 & 65 & 75 & 70 & 80 & 65 & 70 & 50 \\
Ridwan & 90 & 70 & 80 & 90 & 85 & 70 & 70 & 70 \\
\hline
\end{tabular}

Langkah selanjutnya adalah menghitung vector $\mathrm{S}$, data akan di kalikan ,tetapi sebelumnya dilakukan pemangkatan bobot terlebih dahulu Sebagai berikut :

$$
\begin{aligned}
& \text { Wawan }=\left(80^{0.12}\right)\left(85^{0.20}\right)\left(75^{0.12}\right)\left(80^{0.16}\right)\left(50^{0.08}\right)\left(60^{0.12}\right) \\
& \left(70^{0.12}\right)\left(70^{0.08}\right) \\
& =1.69 \times 2.43 \times 1.68 \times 2.02 \times 1.37 \times 1.63 \times 1.66 \times 1.40 \\
& =72.78999532773307 \\
& \text { Andi }=\left(70^{0.12}\right)\left(80^{0.20}\right)\left(70^{0.12}\right)\left(85^{0.16}\right)\left(65^{0.08}\right)\left(80^{0.12}\right) \\
& \left(75^{0.12}\right)\left(75^{0.08}\right) \\
& =1.66 \times 2.40 \times 1.66 \times 2.04 \times 1.40 \times 1.69 \times 1.68 \times 1.41 \\
& =75.9564527949431 \\
& \text { Pitri }=\left(70^{0.12}\right)\left(70^{0.20}\right)\left(75^{0.12}\right)\left(80^{0.16}\right)\left(75^{0.08}\right)\left(85^{0.12}\right) \\
& \left(75^{0.12}\right)\left(80^{0.08}\right) \\
& =1.66 \times 2.34 \times 1.68 \times 2.02 \times 1.41 \times 1.70 \times 1.68 \times 1.42 \\
& =75.63500588998495
\end{aligned}
$$




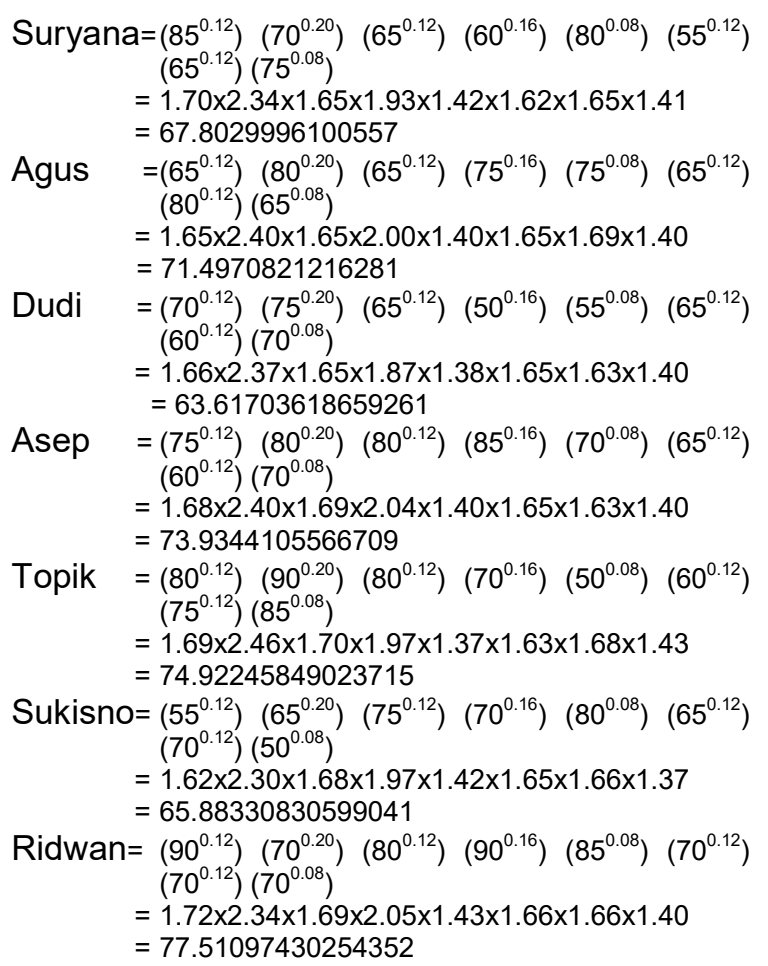

Menghitung nilai Vektor Vi

Setelah nilai vektor di dapat maka selanjutnya adalah menjumlahkan seluruh vector $S$ untuk menghitung vector $\mathrm{V}$ perhitunganya sebagai berikut:

$$
\begin{aligned}
& V i=72.79+75.96+75.64+67.80+71.50+ \\
& 63.62+73.93+74.92+65.88+ \\
& 77.51 \\
& V i=719.55
\end{aligned}
$$

Tabel 4 Tabel Perhitungan Vektor(

\begin{tabular}{llll}
\hline NO & \multicolumn{2}{c}{ Nama } & Hasil perhitungan \\
\hline 1 & Wawan & $=\frac{72.79}{719.55}=0.10116024086914$ \\
2 & Andi & $=\frac{75.96}{719.55}=0.10556084013615$ \\
3 & Pitri & $=\frac{75.64}{719.55}$ & $=0.10511410777705$ \\
4 & Suryana & $=\frac{\frac{67.50}{719.55}}{}=0.094229539943251$ \\
5 & Agus & $=\frac{71.50}{719.55}$ & $=0.09936340861543$ \\
6 & Dudi & $=\frac{63.62}{719.55}$ & $=0.088412077443351$ \\
7 & Asep & $=\frac{73.93}{719.55}$ & $=0.10275069735554$ \\
8 & Topik & $=\frac{74.92}{719.55}$ & $=0.10412620423541$ \\
9 & Sukisno & $=\frac{65.88}{719.55}$ & $=0.091561639858366$ \\
10 & Ridwan & $=\frac{77.51}{719.55}$ & $=0.10772124376631$
\end{tabular}

\section{KESIMPULAN}

Dengan adanya perhitungan algoritma ini perusahaan dapat menentukan dengan jelas kriteria untuk menentuka bonus terhadap karyawan.nilai preferensi terbesar di raih oleh karyawan yang bernama ridwan dengan nilai :0.10772124376631. kemudia di urutkan ke dua di duduki oleh Andi dengan nilai : 0.10556084013615 selanjutnya urutan ketiga oleh pitri dengan nilai : 0.10511410777705 . dengan menggunakan metode Weighted produck yang di terapkan di perusahaan tersebut dapat memudahkan bagian keuangan dan pemilikperusahaan dalam menentukan karyawan yang berhak mendapatkan bonus secara tepat dan akurat.

Berdasarkan hasil dan kesimpulan tentang implementasi metode Weighted produck ,maka saran yang dapat di berikan dalam meningkatkan kualitas adalah bagi pengembang berikutnya di buat aplikasi system pendukung keputusan agar perhitunganya dapat di lakukan secara automatis dan lebih mudah dalam menentukan bonus terhadap karyawan.

\section{REFERENSI}

Ainun, N., Kusumawati, D., Kaharu, S., Suprapto, J., Timur, P., \& Product, W. (2017). Penentuan Bonus Karyawan Menggunakan Weigted Product Pada Perusasahaan Agro Bisnin Palu. 121-126.

Hidayat, M. A., Aksad, H., \& Susanto, B. H. (2015). Penentuan Pemenang Lomba Cosplay Berbasis Weighted Product. Jutisi, 4(1), 653-728.

Hidayat, T., \& Komariah, S. (2020). Pemilihan Siswa-Siswi Berprestasi Menggunakan Metode Weighted Product (WP) Studi Kasus SMP-Al Fitroh Tangerang. Jurnal Teknik Informatika Unis, 7(2), 159-163. https://doi.org/10.33592/jutis.v7i2.398

Irsan, M. (2018). Implementasi Aplikasi Sistem Pendukung Keputusan Kenaikan Jabatan Pegawai Negeri Sipil (Pns) Menggunakan Metode Weight Product Pada Bagian Protokol Dan Dokumentasi Setda Kota Depok. Faktor Exacta, 11(1), 17. https://doi.org/10.30998/faktorexacta.v11i 1.2344

Lestari, S. (2013). Penerapan Metode Weighted Product Model Untuk Seleksi Calon Karyawan. Jurnal Sistem Informasi, 5(1), 540-545.

Marbun, E. D., Simanjuntak, E. R., Siregar, D., \& Afriany, J. (2018). Penerapan Metode Weighted Aggregated Sum Product Assessment Dalam Menentukan Tepung Terbaik Untuk Memproduksi Bihun. Jurnal Riset Komputer (JURIKOM), 5(1), 24-28. http://ejurnal.stmikbudidarma.ac.id/index.php/jurikom\%7C 
Marpaung, N., Handayani, M., \& Yesputra, R. (2018). Sistem Pendukung Keputusan Pemilihan Dosen Terbaik Dengan Metode Weighted Product (WP) Pada STMIK Royal. Seminar Nasional Royal 2018, 9986(September), 267-270.

Naramessakh, K. T., \& Prianto, C. (2019). Otomatisasi Keputusan Pemberian Kredit Pensiun Menggunakan Metode Weighted Product. Efisiensi - Kajian IImu Administrasi, 16(1), 33-48. https://doi.org/10.21831/efisiensi.v16i1.24 475

Oktaviana, R., \& Himawan, H. (2015). Sistem Pendukung Keputusan Untuk Menentukan Pelanggan Terbaik Pada TB. Bangun Jaya Menggunakan Metode Weighted Product (WP). Universitas Dian Nuswantoro, 1-9.

Putra, A. J., Abdillah, L. A., \& Yudiastuti, H. (2016). Penentuan Sekolah Dasar Negeri Terbaik Kota Palembang Dengan Metode Weighted Sum Model ( WSM ) Dan
Weighted Product Model ( WPM ) Menggunakan Visual Basic. Net 2015. Sentikom2016, September, 1-6.

Sambani, E. B., Agustin, Y. H., \& Marlina, R. (2016). Sistem Pendukung keputusan Kenaikan Jabatan Karyawan Plaza Asia Dengan Menggunakan Metode Weighted Product. CSRID (Computer Science Research and Its Development Journal), $8(2)$, https://doi.org/10.22303/csrid.8.2.2016.12 $1-130$

Supriyono, H. (2015). Pemilihan Rumah Tinggal Menggunakan Metode Weighted Product. Khazanah Informatika: Jurnal IImu Komputer Dan Informatika, 1(1), 23. https://doi.org/10.23917/khif.v1i1.1178

Syafitri, N. A., \& Dewi, A. P. (2016). Penerapan Metode Weighted Product Dalam Sistem Pendukung Keputusan Pemilihan Laptop Berbasis Web. SemanTIK, 2(1), 169-176. https://doi.org/10.1016/j.bmc.2010.09.050 